\title{
Sağlık Öğrencilerinde Tüberküloz Prevalansı
}

\author{
The Prevalence of Tuberculosis in Health Students
}

Lale TÜRKMEN ${ }^{1}$, Aydın KIVANÇ²

\begin{abstract}
ÖZ
Tüberküloz (TB), küresel çabalara rağmen yüksek morbidite ve mortalite oranlarıyla günümüzün halk sağlığı sorunlarından biri olmaya devam ediyor. Hem gelişmekte olan hem de gelişmiş ülkelerde, sağlik çalışanları ve öğrenciler maruziyet ve enfeksiyon için önemli bir risk grubunu temsil etmektedir. TB enfeksiyon kontrolünün önemli bileşenlerinden biri, sağlık çalışanlarının gizli tüberküloz enfeksiyonu için rutin olarak taranması ve testi pozitif olanlara kemoprofilaksi uygulanmasıdır. Bu çalışmanın amacı, gelecekte sağlık hizmeti sektöründe aktif olarak görev alacak olan sağlıklı, sağlık teknikeri öğrencileri arasında saflaştırılmış protein türevi (PPD) reaksiyonlarının dağılımını analiz etmek ve skar varlığı, skar sayısı ve PPD reaktivitesi arasındaki korelasyonu belirlemektir. 2017-2020 yılları arasında Sağlık Hizmetleri Meslek Yüksekokulunda öğrenim gören öğrencilerin demografik özellikleri ve PPD deri testi sonuçları ve önceki Bacillus Calmette-Guèrin (BCG) skar sayıs1 retrospektif olarak değerlendirilmiştir. İstatistiksel değerlendirmeler SPSS V.22 programı kullanılarak yapılmıştır. Bağımsız değişkenler sayı ve yüzde ile gösterilmiştir. Bağımlı değişkenlere ise, ki-kare testi uygulanmıştır. Çalışmaya toplam 390 öğrenci dahil edilmiştir. Öğrencilerin \% 13,1'i PPD pozitif olarak bulunmuştur. PPD pozitiflik oranları, \%10,0 (15-20 mm) ve \%3,1 (20 ve üzeri mm) olarak tespit edilmiştir. Öğrencilerin skar sayıları sıfırdan ikiye kadar değişmiştir. BCG skar sayıları ve PPD endürasyon çapları arasındaki ilişki istatistiksel olarak anlamlı bulunmuştur $(p<0,05)$. BCG skarı olmayanların öğrencilerin tamamı PPD negatiftir. Sağlık teknikeri adayları arasında PPD negatifliği ve BCG pozitifliğinin yüksek oranı aşı kaynaklı koruyucu bağışıklığın bir göstergesidir.
\end{abstract}

Anahtar Kelimeler: Tüberküloz, PPD Deri Testi, BCG, Sağlık Teknikeri Öğrencileri.

\begin{abstract}
Tuberculosis (TB), continues to be one of today's public health problems with high morbidity and mortality rates despite global efforts. Healthcare professionals and students represent an important risk group for exposure and infection in both developing and developed countries. One of the important components of tuberculosis infection control is the routine screening of healthcare workers for latent tuberculosis infection and chemoprophylaxis for positive ones. The aim of this study is to analyze the distribution of purified protein derivative (PPD) reactions among healthy health technician students who will be active in the healthcare sector in the future and to determine the correlation between scar presence, scar number and PPD reactivity. The number of previous Bacillus Calmette-Guèrin (BCG) traces between the years 2017-2020 were evaluated retrospectively by demographic characteristics and PPD test. Statistical evaluations were made using the SPSS V.22 program. Independent variables are shown with numbers and percentages. Chi-square test was applied to dependent variables. A total of 390 students were included in the study. $13,1 \%$ of the students were found to be PPD positive. PPD positivity rates were determined as $10,0 \%(15-20 \mathrm{~mm})$ and $3,1 \%$ (20 and above $\mathrm{mm})$. The number of scars of the students varied from zero to two. The relationship between BCG scar numbers and PPD induration diameters were statistically significant $(p<0,05)$. All of the students without BCG scar were PPD negative. The high rate of PPD negativity and BCG positivity among health technician candidates is an indicator of vaccineinduced protective immunity.
\end{abstract}

Keywords: Tuberculosis, PPD Skin Test, BCG, Health Technician Students.

\footnotetext{
${ }^{1}$ Dr. Öğretim Üyesi Lale TÜRKMEN, Mikrobiyoloji Gazi Üniversitesi,Sağlık Hizmetleri Meslek Yüksekokulu, lturkmen@gazi.edu.tr, ORCID: 0000-0003-4856-3809

${ }^{2}$ Dr. Öğretim Üyesi, Aydın KIVANÇ, Halk sağlığı, Gümüşhane Üniversitesi, Sağlık Bilimleri Fakültesi,aydinkivanc@gümüşhane.edu.tr, ORCID:0000-0002-5942-9077 


\section{GİRIŞ}

Tüberküloz (TB), küresel çabalara rağmen yüksek morbidite ve mortalite oranlarıyla günümüzün halk sağlığı sorunlarından biri olmaya devam etmektedir. Dünya Sağlık Örgütüne (WHO) göre, küresel olarak, 1,7 milyar insanın Mycobacterium tuberculosis ile enfekte olduğu ve \%5-10'nun yaşamları boyunca aktif TB geliştireceği tahmin edilmektedir. ${ }^{1}$ Salgınla mücadele etmek için DSÖ, 2015 yılında TB insidansını 2030 yılına kadar \%95 oranında azaltmayı amaçlayan "SON TB" stratejisini başlatmıştır. $^{1}$

Dünyada ve Türkiye'de kanıta dayalı gelişmeler temel alınarak etkili tüberküloz enfeksiyon kontrol programları geliştirilmekte olup, yönergeler ve standartlar oluşturulmaktadır. ${ }^{1,2}$ Türkiye'de ulusal TB programının temelini, hastaların erken teşhisi ve etkili tedavilerinin sağlanması oluşturmaktadır. ${ }^{2}$ Ancak, ülkemizde yasal olarak bildirimi zorunlu bir hastalık olan TB hastalığ 1 bildirimleri halen yeterli düzeyde değildir. ${ }^{3}$

Hem gelişmekte olan hem de gelişmiş ülkelerde, sağlık çalışanları ve öğrencileri, TB maruziyeti ve enfeksiyonu için önemli bir risk grubunu oluşturmaktadır. ${ }^{2-6}$ Mevcut verilerde, TB insidans oranlarının sağlık çalışanları arasında genel popülasyondan daha yüksek olduğunu göstermektedir. ${ }^{7-11}$

Türkiye'deki çalışmalarda tüberküloz tanısı konmuş sağlık çalışanlarında insidans oranları yüz binde 252 ile 670 arasında değişmektedir. $\mathrm{Bu}$ veri sağlık çalışanlarında toplumdan 10 kat daha fazla tüberküloz hastalığını ve tüberküloz bulaşına karşı önlem alınması gerektiğini göstermektedir. ${ }^{11}$ Sağlık personelinin latent tüberküloz enfeksiyonu (LTBE) için düzenli olarak taranması ve sonucu pozitif çıkanlara kemoprofilaksi uygulanması, tüberküloz enfeksiyon kontrolünün temel bileşenlerinden biridir. ${ }^{2,5,6}$ LTBE mücadelesi, asemptomatik bireylerin tespitini ve tedavi edilmesini gerektirmektedir. ${ }^{2}$

Hastalık kontrol ve önleme merkezleri (CDC) ve iş güvenliği ve sağlığı idaresi (OSHA), tüberküloz enfeksiyon riski açısından sağlık çalışanlarını düzenli tarama programlarına büyük öncelik vermektedir., ${ }^{5,6}$ Geçtiğimiz yüzyılda bu amaç için tek pratik uygulama PPD deri testidir (Mantoux testi/tüberkülin deri testi). ${ }^{12-14}$

PPD taramasının etkinliğini ile ilgili önceki çalışmalar, daha çok sağlık çalışanlarına odaklanmış olup gelecekteki sağlık çalışanları için çok az çalışma mevcuttur. ${ }^{15}$ Bacillus Calmette-Guérın (BCG) aşısının uygulandığı ülkemizde, tüberkülin pozitifliği bilinmemekte ve PPD pozitiflik sınırı konusunda erişkin yaş grubunda veriler bulunmamaktadır. ${ }^{11}$ PPD araștırmaları, ortalama yıllık enfeksiyon riskinin tahmin edilebileceği verileri sağlamaktadır. $\mathrm{Bu}$ parametre bir popülasyondaki latent tüberkülozun güvenilir bir göstergesi olarak kabul edilmektedir. Ek olarak, düzenli aralıklarla tekrarlanan araştırmalarla zaman içindeki enfeksiyon paterni belirlenebilir. Ulusal TB programlarının hazırlanmasinda ve değerlendirilmesinde epidemiyolojik yaklaşımlar değerli araçlardır. ${ }^{16}$

$\mathrm{Bu}$ çalıșmanın amacı, gelecekte sağlık hizmeti sunumunda aktif olarak görev alacak olan sağlıklı, sağl1k teknikeri öğrencileri arasında PPD reaksiyonlarının dağılımını analiz etmek ve skar varlığı, skar oranı ve PPD reaktivitesi arasındaki korelasyonu analiz etmektir.

\section{MATERYAL VE METOT}

$\mathrm{Bu}$ retrospektif çalışma, Ekim 2020 yılında Ankara, Gazi Üniversitesi, Sağlık Hizmetleri Meslek Yüksekokulunda gerçekleştirilmiştir. Sağlık teknikeri öğrencileri, müfredat gereği hastane ortamlarında yaz staji ve mesleki uygulama eğitimine tabi tutulurlar. $\mathrm{Bu}$ süreçlerde öğrencilerin hastalarla temasları artmaktadır 
programlar ve PPD test sonuçları ve BCG

(1. sınıf 30 gün ve 2 . sınıf 42 iş günü staj). Risk grubunda yer alan sağlık teknikeri öğrencileri stajlara başlarken tüberkülin deri testi yaptırmak zorunda olup, tarama yapma görevi verem savaşı dispanserleri tarafindan gerçekleştirilmektedir. Türkiye de PPD reaksiyonunun yorumlanmasında kullanılan kriterler Tablo 1'de verilmiştir. ${ }^{2}$

\section{Verilerin Toplanması}

Gazi Üniversitesi Sağlık Hizmetleri Meslek Yüksekokulundaki Tibbi Laboratuvar Teknikleri (TLT), Tibbi Dökümantasyon ve Sekreterlik (TDS), Tibbi Görüntüleme Teknikleri (TGT) ve Patoloji (PAT) programlarında, 2017-2020 y1lları arasında öğrenim gören, toplam 390 öğrenci çalışmaya dahil edilmiştir. $\mathrm{Bu}$ çalışmada, öğrencilerin yaş, cinsiyet, öğrenim gördükleri skar sayısı kaydedilmiştir.

\section{Verilerin Analizi}

İstatistiksel değerlendirmeler SPSS V.22 programı kullanılarak yapılmıştır. Bağımsız değişkenler sayı ve yüzde ile gösterilmiştir. Bağımlı değişkenlere ise, ki-kare testi uygulanmıştır. İstatistiksel olarak anlamlılık düzeyi $p<0,05$ olarak kabul edilmiştir.

\section{Araştırmanın Etik Yönü}

Araştırmanın veri toplama aşaması, Gazi Üniversitesi, Sağlık Hizmetleri Meslek Yüksekokulunda gerçekleştirilmiştir. Araştırma ile ilgili Yüksekokul Müdürlügün'den yazılı izin ve Gümüşhane Üniversitesi Bilimsel Araştırma ve Yayın Etiği Kurulu'ndan Etik kurul izni alınmıştır (Karar tarihi: 25.08.2020, Karar No: 2020/8).

Tablo 1. Ülkemizde Tüberkülin Deri Testi (TDT) Reaksiyonunun Yorumlanması ${ }^{2}$

\begin{tabular}{|c|c|}
\hline BCG'lilerde & \\
\hline $0-5 \mathrm{~mm}^{*}$ & Negatif kabul edilir. \\
\hline 6-14 mm* & Negatif kabul edilir (BCG'ye ya da TDM'lere bağlı olabilir). \\
\hline $15 \mathrm{~mm}$ ve üzeri & Pozitif kabul edilir. \\
\hline BCG'sizlerde & \\
\hline $0-5 \mathrm{~mm} *$ & Negatif kabul edilir. \\
\hline $6-9 \mathrm{~mm}^{*}$ & Negatif kabul edilir (TDM'lere bağl1 olabilir). \\
\hline $10 \mathrm{~mm}$ ve üzeri & Pozitif kabul edilir. \\
\hline Bağıșıklığı baskılanmış kișilerde** & $5 \mathrm{~mm}$ ve üzeri pozitif kabul edilir. \\
\hline
\end{tabular}

\section{BULGULAR VE TARTIȘMA}

Kat1lımciların \%44,6's1 TGT, \%28,7'si TDS, \%15,1'i TLT ve \%11,5'i PAT programında öğrenim görüyordu. Kızlar örneklemin \%66,2 oluşturdu. Öğrencilerin $\% 33,5$ 'i $18-20$ ve \%66,5'i $21-25$ yaş aralığında idi. Öğrencilerin tanımlayıcı özellikleri Tablo 2'de sunulmuştur.
Tablo 2. Öğrencilerin Demografik Özellikleri $(\mathbf{n}=390)$

\begin{tabular}{lcc}
\hline Özellikler & Sayı & \% \\
\hline Yaş & & \\
$18-20$ & 131 & 33,5 \\
$21-25$ & 259 & 66,5 \\
\hline Cinsiyet & & \\
K1z & 258 & 66,2 \\
Erkek & 132 & 33,8 \\
\hline Programlar & & \\
TGT & 174 & 44,6 \\
TDS & 112 & 28,7 \\
TLT & 59 & 15,1 \\
PAT & 45 & 11,5 \\
\hline \%: Yüzde & &
\end{tabular}


Araştırma grubunun PPD endürasyon dağılımı Tablo 3'te gösterilmektedir. Tüm sağlık teknikeri grupları arasında \%86,9 oranında PPD negatifliği $(0-14 \mathrm{~mm})$ tespit edildi. PPD pozitiflik oranları \%10,0 (15-20 $\mathrm{mm}$ ) ve $\% 3,1$ (20 ve üzeri mm) idi.

Tablo 3. Öğrencilerin PPD Test Sonuçlarına Göre Dağılımı

\begin{tabular}{llr}
\hline PPD endürasyon (mm) & Sayı & \% \\
\hline $0-14$ & 339 & 86,9 \\
$15-20$ & 39 & 10,0 \\
$>20$ & 12 & 3,1 \\
\hline Toplam & $\mathbf{3 9 0}$ & $\mathbf{1 0 0}$ \\
\hline \%: Yüzde & &
\end{tabular}

Tablo 4'te belirtildiği gibi 18 öğrenci de $(\% 4,6)$ BCG skar1 yoktu, 261'de $(\% 66,9)$ bir skar, 111 'inde $(\% 29,5)$ iki skar vard1. Bir skar olanlar gruplar arasında en büyük yüzdeyi oluşturuyordu. 1 skar olan öğrenciler arasinda 231'i (\%88,5) PPD negatif (0-14 $\mathrm{mm})$ iken, 27'si $(\% 10,4) 15-20$ ve 3 'ü $(1,1)$ $>20$ ve üzeri PPD endürasyon çapına sahipti. 2 skar olan öğrenciler arasında 90' $1(\% 81,0)$, 0-14 mm, 12'si $(\% 10,9) 15-20$ ve 9'u $(\% 8,1)$ 20 ve üzeri endürasyon çapına sahipti. Öğrencilerin BCG skar sayılarıyla PPD endürasyon çapları arasındaki anlamlı bir ilişki vardı $\quad(p<0,05)$.

Tablo 4. Öğrencilerin BCG Sonuçlarının PPD Endürasyon Boyutlarına Göre Dağılımı

\begin{tabular}{|c|c|c|c|c|c|c|c|c|c|}
\hline \multirow[t]{3}{*}{ BCG skar } & \multicolumn{6}{|c|}{ PPD endürasyon çapı (mm) } & \multicolumn{2}{|c|}{ Toplam } & \multirow[t]{3}{*}{$\mathbf{x}^{2}$} \\
\hline & \multicolumn{2}{|c|}{$0-14$} & \multicolumn{2}{|c|}{$15-20$} & \multicolumn{2}{|c|}{$>20$} & & & \\
\hline & $\mathbf{S}$ & $\% x$ & $\mathbf{S}$ & $\% \mathbf{x}$ & $\mathbf{S}$ & $\% \mathbf{x}$ & Sayı & $\% \mathrm{xx}$ & \\
\hline Yok & 18 & 100,0 & 0 & 0,0 & 0 & 0,0 & 18 & 4,6 & 36,0 \\
\hline 1 skar & 231 & 88,5 & 27 & 10,4 & 3 & 1,1 & 261 & 66,9 & 124,1 \\
\hline 2 skar & 90 & 81,0 & 12 & 10,9 & 9 & 8,1 & 111 & 29,5 & 114 \\
\hline Toplam & 339 & 86,9 & 39 & $\mathbf{1 0 , 0}$ & 12 & 3,1 & 390 & 100,0 & 274,1 \\
\hline
\end{tabular}

Sağl1k teknikeri öğrencileri arasında en yüksek PPD pozitifliği \%20,0 ile PAT programı öğrencilerinde oldu. Daha sonra, TLT $(\% 15,3)$, TDS $(\% 15,2)$ ve TGT $(\% 9,2)$ programı öğrencilerinde sirasıyla PPD pozitifliği saptandı. PPD endürasyon çapları ile meslek kategorileri karşılaştırıldığında anlamlı farklılıklar tespit edildi $(p<0,05)$ (Tablo 5).

Tablo 5. PPD Sonuçlarının Programlara Göre Dağılımı

\begin{tabular}{|c|c|c|c|c|c|c|c|c|c|c|c|}
\hline \multirow[t]{3}{*}{ PPD } & \multicolumn{8}{|c|}{ Programlar } & \multicolumn{2}{|c|}{ Toplam } & \multirow[t]{2}{*}{$\mathbf{x}^{2}$} \\
\hline & & & & & & & & & & & \\
\hline & Sayı & $\% x$ & Sayı & $\% \mathbf{x}$ & Sayı & $\% \mathrm{x}$ & Sayı & $\% x$ & Sayı & $\% \mathrm{x}$ & \\
\hline $0-14$ & 50 & 84,7 & 36 & 80,0 & 158 & 90,8 & 95 & 84,8 & 339 & 86,9 & 108 \\
\hline $15-20$ & 9 & 15,3 & 6 & 13,3 & 10 & 5,7 & 14 & 12,5 & 39 & 10,0 & 2,42 \\
\hline$>20$ & 0 & 0 & 3 & 6,7 & 6 & 3,5 & 3 & 2,7 & 12 & 3,1 & 6 \\
\hline Toplam & 59 & 15,1 & 45 & 11,5 & 174 & 44,6 & 112 & 28,8 & 390 & 100,0 & 116,42 \\
\hline
\end{tabular}

Tarihsel olarak, birçok hastanedeki enfeksiyon kontrol politikaları, sağlık çalışanlarının istihdam öncesi ve sonrası aynı zamanda sağlı hizmeti öğrencilerinin klinik çalışmaların başlangıcında PPD ile rutin taranmasını önermiştir. 2,5,6,14,15 BCG aşılamasından sonra PPD pozitif test reaksiyonları ve BCG skarlaşma oranları dünyada ve bölgeler arasında farklılık gösterir. ${ }^{17} \quad$ Türkiye'de $\quad$ TB kontrol uygulamaları kapsamında, TB'ye maruz kalma riski taşıyan sağlık çalışanlarında gizli TB enfeksiyonu için seri taramalar yapılmaktadır. $^{2}$ Bir tüberkülin reaksiyonu, hastaya özgü belirli risk faktörleri ile birlikte endürasyon çapına göre pozitif olarak sınıflandırılır. ${ }^{12,13}$ Bağışıklık sistemi normal olan sağlıklı bir kişide, 15 mm'den büyük veya eşit endürasyon pozitif bir deri testi olarak kabul edilir., ${ }^{2,12,13} \mathrm{Bu}$ çalışmada tüm sağlık teknikeri öğrencilerinde PPD pozitiflik oranı \%13,1'di. Öğrencilerin \%10,0'u 15-20 $\mathrm{mm}$ ve $\% 3,1^{\prime} \mathrm{i}>20 \mathrm{~mm}$ endürasyon çapına sahipti (Tablo 3). Bu bulgumuz, Türkiye'de sağlık çalışanları ve öğrenciler arasında yapılan çalışmalardan daha düşük oranda 
bulunmuştur. Bozkanat ve ark. sağlık çalışanlarında PPD pozitiflik oranını \%58,8 olarak bildirmişlerdir. ${ }^{18}$ Hizel ve ark. BCG aşılamasının yetişkinlerde tüberkülin reaktivitesi ve güçlendirici etkisini araştırdıkları çalışmalarında birinci sınıf tıp öğrencilerinde $\% 59,1$ ile yüksek PPD pozitif oranlar tespit etmişlerdir. ${ }^{19}$ İmre ve ark. sağlık çalışanlarıyla risk grubunda olmayan bireylerin PPD sonuçlarını sırasıyla \%21,8 ve $\% 8,2$ bildirmişlerdir. ${ }^{20} \mathrm{Bu}$ bulgumuz düşük ve orta gelirli diğer ülkelerde yapılan çalışmalara göre daha düşüktü. ${ }^{21,22,23}$

Çalışmamızda, PPD pozitifliğin düşük oranda olması araştırma popülasyonunun henüz sağlık hizmetine başlamamış sağlık teknikeri adaylarından oluşması ve düzenli eğitim sayesinde TB ve enfeksiyon kontrol önlemlerine yönelik iyi uygulamaları ile ilişkili olabilir. Nitekim, sağlık kurumlarında idari, kişisel ve mühendislik kontrolleri dahil olmak üzere çoklu enfeksiyon kontrol önlemlerinin uygulanmasının TB enfeksiyonunun azaltılmasında etkili olduğu çalışmalarla kanıtlanmıştır. ${ }^{24}$ Bununla beraber PPD pozitiflik oranlarımız, mikobakterilere doğal maruziyeti gösterebildiği gibi, önceki BCG aşılanması veya birçok sosyo-ekonomik faktörlede ilişkili olabilir. $\mathrm{Bu}$ parametrelerin göreceli etkisi popülasyonlar arasında değişir. Bütün bunların yanında verilerimizi değerlendirirken PPD testinin kısmen BCG ile çapraz reaksiyonlar gösterebildiğini, tüberküloz dışı mikobakterilere özgüllüğünün olmayışını ve PPD uygulananların bazılarının kutanöz anerji sergileyebileceği de göz önünde bulundurulmalıdır. ${ }^{2,12,13,16}$

Türkiye'de rutin aşılama programında yer alan BCG, şu anda TB'a karşı mevcut olan tek aşıdır ve küresel olarak her yıl 100 milyondan fazla BCG uygulanmaktadır. ${ }^{3,25}$ BCG aşısı genellikle skar oluşumuna ve PPD reaksiyonuna yol açmaktadır. ${ }^{16}$ Aşı yaygınlığı ve/veya etkinliği ile ilgili çalışmalarda, BCG aşısı skarının varlığı veya yokluğu, aş1lama durumunun bir göstergesi olarak kullanılır. Aş1lanan bireylerin çoğunda skar oluşur ve bu stabil bir fenomendir. ${ }^{26,27}$
$\mathrm{Bu}$ çalışmada, öğrencilerin \%96,4'ün de BCG skarı bulunurken skar sayıları 1 ve 2 olarak saptanmıştır (Tablo 4).

BCG skar varlığı ile ilgili sonucumuz, önceki aşılamanın bir göstergesi/kanıtı olarak değerlendirilmiş ve aynı zamanda etkili aş1lamanın göstergesi olarak yorumlanmıştır. ${ }^{20,27}$

Çalışmamız skar varlığı/sayısı ile PPD reaktivitesi arasında pozitif bir ilişki olduğunu göstermiştir. $\mathrm{Bu}$ bulgumuz $\mathrm{BCG}$ skar varlığ 1 ile PPD reaktivitesi arasında pozitif bir ilişki olduğunu gösteren İmre ve ark. yaptıkları çalışmayla uyumludur. ${ }^{20}$ Bununla beraber ilişkinin tespit edilmediği çalışmalar da vardır. ${ }^{16,19,28,29}$

Çalışmamız da en çarpıcı bulgu, BCG skarı olmayanların $(\% 4,6)$ tamamının PPD negatif olmasıydı. Gelecek de sağlık hizmeti sunacak olan sağlik teknikeri öğrencilerin de bu düşük oran bile son derece önemlidir. Sağlıklı bir yetişkinin aşılanmasından sonra skar oluşumu eksikliği aşılama prosedürünün yetersiz olduğunu veya bağışıklık yanıtının farklı olduğunu gösterebilir ${ }^{16}$. Bununla beraber bu sonucumuz TB kontrol protokollerinin eksikliğine ve aynı zamanda öğrencilerin tüberküloz enfeksiyonu hakkında farkındalıklarının düşük olduğu varsayımına da yol açabilir.

PPD reaksiyonları programlara göre değerlendirildiğinde, en yüksek PPD negatifliği $\% 90,8$ ile TGT'de gözlenmiştir. Bunu sirasiyla TDS $(\% 84,8)$ ve TLT $(\% 84,7)$ programları izlemiştir (Tablo 5). Bu bulgumuz TGT öğrenci sayısının diğer programlara göre yüksek olması ile ilişkilendirilebilir.

Araştırmamızda, en yüksek PPD pozitif oranları PAT programı öğrencilerinde bulunmuştur. $\mathrm{Bu}$ biyolojik riski yüksek bir ortamda bulunmalar1 ${ }^{6,30}$ veya enfeksiyon kontrol önlemlerine uyumlarının düşük olması ile açıklanabilir. ${ }^{24}$.

Çeşitli çalışmaların bulguları iş kategorisine göre farklılık göstermesi ve denek sayımızın bir meslek grubunu temsil etmemesi gerektiği gerçeği, bu bulgu için bir açıklama yapmayı zorlaştırmaktadır. ${ }^{10}$ 
Bununla beraber, TB riskinin belli bir meslek grubuna atfedilemeyeceğini ve TB'ye maruz

kalma riskinin tüm sağlık çalışanlarını ilgilendirdiği görüşündeyiz. ${ }^{31}$

\section{SONUÇ VE ÖNERILER}

Sağlık teknikeri adayları arasında PPD negatifliği ve BCG pozitifliğinin yüksek oranı aşı kaynaklı koruyucu bağışıklığın bir göstergesidir. Bununla beraber PPD pozitif sonuçlar, PPD tarama sonuçlarının (tüm deri testi sonuçları, demografik, klinik ve takip bilgileri) analiz edilmesinin gerekliliğini ortaya koymaktadır. Bu noktada, TB'a maruz kalma riski olan sağlık teknikeri adaylarında etkili idari, çevresel ve kişisel koruyucu önlemlerin uygulanmasinda denetim stratejilerinin geliştirilmesini ve aynı zamanda, etkin bir iş sağlığı ve güvenliği eğitimi almalarını bir kez daha tavsiye ediyoruz.

\section{KAYNAKLAR}

1. World Health Organisation [Internet]. (2019). "Global Tuberculosis Report." Geneva: The Organization. Erişim https://apps.who.int/iris/bitstream/handle/10665/329368/97892 41565714-eng.pdf?ua=1. Erişim tarihi: 15 Mayıs 2020 .

2. Sağlık Bakanlığı Tüberküloz Tanı ve Tedavi Rehberi. (2019). 2. Bask1, Ankara Erişim: https://hsgm.saglik.gov.tr/depo/birimler/tuberkuloz_db/haberler /Tuberkuloz_Tani_Ve_Tedavi_Rehberi_Tuberkuloz_Tani_ve Tedavi_Rehberi.pdf..Erişim tarihi:12 Temmuz 2020.

3. Şimșek, A., Özkan, S. (2019). "Ankara İlinde Yapılan Aktif Sürveyans Uygulamasının Tüberküloz Hastalarının Kayıt ve Takibine Katkısının Değerlendirilmesi." Ankara Medical Journal, 19 (1), 71-82. https://doi: 10.17098/amj.542289

4. Xu, Y., Schwartzman, K. (2010). "Referrals for Positive Tuberculin Tests in New Health Care Workers and Students: A Retrospective Cohort Study." BMC Public Health, 10 (28), 1-7. https://doi.org/10.1186/1471-2458-10-28

5. Jensen, P.A., Lambert, L.A., Iademarco, M.F. (2005) "Guidelines for Preventing the Transmission of Mycobacterium tuberculosis in Health care Facilities, Morbidity and Mortality Weekly Report (MMWR)." Centers for Disease Control and Prevention (CDC), 54 (RR-17), 1-141.

6. Occupational Safety and Health Administration. (1997) Occupational Exposure to Tuberculosis: Proposed Rule Federal Register, $62 \quad$ (201), 54159-54209. https://www.osha.gov/SLTC/etools/hospital/references.html

7. Bo, M., Zotti, C.M. (2016). "European Policies on Tuberculosis Prevention in Healthcare Workers: Which Role for BCG? A Systematic Review." Human Vaccines \& Immunotherapeutics, $12 \quad$ (11), 2753-2764. https://doi.org/10.1080/21645515.2016.1200776

8. Kinikar, A., Chandanwale, A., Kadam, D., Joshi, S., Basavaraj, A. et al. (2019). High Risk for Latent Tuberculosis Infection Among Medical Residents and Nursing Students in India. PloS One, $14 \quad$ (7), 1-12 https://doi.org/10.1371/journal.pone.0219131.

9. Uden, L., Barber, E., Ford, N., Cooke, G.S. (2017). "Risk of Tuberculosis Infection and Disease for Health Care Workers: An Updated Meta-Analysis." Open Forum Infectious Diseases, 4 (3), 1-7. https://doi.org/10.1093/ofid/ofx137.

10. Peters, C., Kozak, A., Nienhaus, A., Schablon, A. (2020). "Risk of Occupational Latent Tuberculosis Infection among Health Personnel Measured by Interferon-Gamma Release Assays in Low Incidence Countries-A Systematic Review and MetaAnalysis." International Journal of Environmental Research and $\begin{array}{llll}\text { Public } & \text { Health, } & 17 & \text { (2), }\end{array}$ https://doi.org/10.3390/ijerph17020581.

11. Özkara, Ş. (2000). "Sağlık Çalışanları ve Tüberküloz.” Flora, 5 (2), 90-98.
12. Nayak, S., Acharjya, B. (2012). "Mantoux Test and Its Interpretation." Indian Journal of Dermatology. 3 (1), 2-6. https://www.idoj.in/text.asp?2012/3/1/2/93479.

13. Pahal, P, Sharma S. (2020). "PPD Skin Test." Treasure Island (FL): StatPearls Publishing. Erișim: https://www.ncbi.nlm.nih.gov/books/NBK556037/. Erişim tarihi:1 Eylül 2020

14. Hotta, K., Ogura1, T., Nishii, K., Kodani, T., Onishi, M., Shimizuet, Y. et al. (2007). "Whole blood interferon-gamma assay for baseline tuberculosis screening among Japanese healthcare students." PLoS One, 2 (8), 1-7. https://doi.org/10.1186/2193-1801-2-440.

15. Xu, Y., Schwartzman, K. (2010). "Referrals for Positive Tuberculin Tests in New Health care Workers and Students: A Retrospective Cohort Study." BMC Public Health. 10 (28), 2-7. https://doi.org/10.1186/1471-2458-10-28

16. Fjällbrant, H. (2008). "BCG Vaccination and the Tuberculin Skin Test in a Country with Low Prevalence of Tuberculosis: Epidemiological and Immunological Studies in Healthy Subjects." Sahlgrenska Academy University of Gothenburg Sweden. Erișim: http://hdl.handle.net/2077/18321. Erisim tarihi: 14 Eylül 2020.

17. Ghaderi, R. (2017). "A New Formula for BCG Scar and Tuberculin Test Response." MOJ Immunol, 5 (5), 1-4. https://doi: 10.15406/moji.2017.05.00171

18. Bozkanat, E., Kaya, H., Sezer, O., Caliskan, T., Kilic, E., Ciftci, F. et al. (2016). "Comparison of Tuberculin Skin Test and quantiferon-TB Gold in Tube Test for Diagnosis of Latent Tuberculosis Infection in Health care Workers: A Cross Sectional Study." Journal of Pakistan Medical Association, 66 (3), 270-274.

19. Hizel, K., Maral, I., Karakus, R., Aktas, F. (2004). "The Influence of BCG Immunisation on Tuberculin Reactivity and Booster Effect in Adults in a Country with a High Prevalence of Tuberculosis." Clinical Microbiology and Infection, 10 (11), 980-983. https://doi.org/10.1111/j.1469-0691.2004.00970.x

20. İmre, A., Arslan-Gülen, T., Koçak, M., Baş-Şarahman, E., Kayabaş, Ü. (2020). "Sağlık Hizmeti Sunan Hastane Calıșanlarıyla Risk Grubunda Olmayan Sağlıklı Bireylerin Tüberkülin Deri Testi Sonuçlarının İrdelenmesi." Klimik Dergisi, 33 (1), 19-23.

21. Casas, I., Esteve, M., Guerola, R., Latorre, I., Villar-Hernández, R., Mena, G. et al. (2020) "Serial Testing of Health Care Workers for Tuberculosis Infection: A prospective cohort study." PLoS One ,15 (7), 1-12 https://doi.org/10.1371/journal.pone.0235986. 
22. Uden, L., Barber, E., Ford, N., Cooke, G.S. (2017). "Risk of Tuberculosis Infection and Disease for Health Care Workers: An Updated Meta-Analysis." Open Forum Infectious Diseases, 4 (3), 1-7. https://doi: 10.1093/ofid/ofx137.

23. Salehi, M., Mood B.S., Metanat, M. (2016). "Positive Tuberculin Skin Test Among Health Care Workers: Prevalence and Risk Factors in Teaching Hospitals of a Highly Endemic Region for Tuberculosis, Zahedan, Iran.” Int J Infect, 3 (3), 1-4. https://doi: 10.17795/iji-36158.

24. Chen, B., Gu, H., Wang, X., Wang, F., Peng, Y., Ge, E. et al. (2019) "Prevalence and Determinants of Latent Tuberculosis Infection Among Frontline Tuberculosis Healthcare Workers in Southeastern China: A multilevel analysis by individuals and health facilities." Int J Infect Dis, 79, 26-33. https://doi: 10.1016/j.ijid.2018.11.010.

25. World Health Organization [Internet]. (2012). "Information Sheet Observed Rate of Vaccine Reactions Bacille CalmetteGuérin (BCG) Vaccine." Geneva: The Organization. https://www.who.int/vaccine safety/initiative/tools/BCG_Vacci ne_rates_information_sheet.pdf?ua $=1$.

26. Dhanawade, S.S., Kumbhar, S.G., Gore, A.D., Patil, V.N. (2015). "Scar Formation and Tuberculin Conversion Following BCG Vaccination in Infants: A Prospective Cohort Study." Journal of Family Medicine and Primary Care, 4 (3), 384-387. https://doi: 10.4103/2249-4863.161327.

27. Jason, J., Archibald, L.K., Nwanyanwu, O.C., Kazembe, P.N., Chatt, J.A., Norton, E. et al. (2002). "Clinical and Immune Impact of Mycobacterium bovis BCG Vaccination Scarring." Infection and Immunity, 70 (11). https://doi:6188-6195. 10.1128/IAI.70.11.6188-6195.2002

28. Ertürk, A., Çalışır, H., Uğurman, F., Balbay, Ö.A., Öğretensoy, M. (2000). "Atatürk Göğüs Hastalıkları ve Cerrahisi Merkezi Personelinde Tüberkülin Sensitivitesi ve Mikrofilm Çalışması." Solunum Hastalıkları, 11 (1), 60-69.

29. Ciesielski, S.D. (1995). "BCG Vaccination and the PPD Test What the Clinician Needs to Know." The Journal of Family Practice, 40, 76-80.

30. Sugita, M., Tsutsumi, Y., Suchi, M., Kasuga, H., Ishiko, T. (1990). "Pulmonary tuberculosis. An Occupational Hazard for Pathologists and Pathology Technicians in Japan." Acta Pathologica Japonica, 40 (2), 116-127. https://doi: 10.1111/j.1440-1827.1990.tb01550.x

31. Bo, M., Zotti, C.M. (2016). "European Policies on Tuberculosi Prevention in Healthcare workers: Which role for BCG? A Systematic Review." Human Vaccines and Immunotherapeutics, $12 \quad$ (11), 2753-2764. https://doi:10.1080/21645515.2016.1200776 